perspectivas

a debate EI marco legal para la protección del patrimonio paleontológico. ¿Qué pasa en tu comunidad?

| coordina Eloísa Bernáldez Sánchez

\title{
Algunas reflexiones sobre la gestión del patrimonio paleontológico por parte de las administraciones españolas
}

José Ignacio Canudo | catedrático de Paleontología y director del Museo de Ciencias Naturales de la Universidad de Zaragoza URL de la contribución <www.iaph.es/revistaph/index.php/revistaph/article/view/4156>

Los fósiles tienen un indudable valor patrimonial por eso tiene sentido su inclusión en las leyes de patrimonio cultural o natural. Es una polémica estéril seguir discutiendo si su ubicación es más adecuada en uno u otro ámbito, lo importante es que la administración diseñe y favorezca las estrategias de conservación, protección e investigación de los fósiles independientemente de su consideración de cultura o de medio ambiente. La inclusión de la palabra investigación es imprescindible en esta reflexión al ser los fósiles un objeto científico descrito y valorado en revistas especializadas. Sirva estas palabras para dar el punto de vista de un científico con más de 30 años de experiencia en trabajos de campo paleontológicos en España y en otros países, lo incluye casi un centenar de actuaciones paleontológicas aprobadas y tuteladas por diferentes administraciones.

Las actuales leyes de regulación de recogida de fósiles en España tienen algunos aspectos claramente mejorables. En muchos casos se trata de normas conjuntas del patrimonio paleontológico y arqueológico que no discriminan sus diferencias metodológicas. Resulta, por ejemplo, difícil de entender que recoger trilobites del Cámbrico sea considerada como excavación, aunque se usen martillos y escoplos en su extracción. Las comunidades con paleontólogos en la administración son capaces de aplicar las leyes desde un punto lógico, entendiendo las singularidades del patrimonio fosilífero, pero sin duda es insuficiente. Las leyes de patrimonio cultural en vigor no contemplan las diferencias en la recuperación de los fósiles y los objetos arqueológicos en el campo, estando desarrolladas desde el punto de vista únicamente arqueológico. Sería un paso necesario que las diferentes comunidades autónomas hicieran cambios en sus respectivas leyes de patrimonio cultural de manera que contemplaran la singularidad de la recolección de los fósiles por parte de los investigadores.

Otro aspecto incluido en las leyes de patrimonio cultural es considerar a todos los fósiles como bien a conservar. Lo cual resulta irrealizable al carecer de sentido proteger todo el territorio donde se encuentran los fósiles. Así hay formaciones geológicas donde se acumulan tal cantidad de macro y microfósiles que es utópico, ni tiene sentido proteger, ni nunca se hará. Reconozco que los límites entre lo que sería un fósil a proteger y el que no es un tema discutible, pero sin duda esta discusión nos permitiría una mejor protección de los bienes con verdadero interés patrimonial y científico. Esto requiere esfuerzos económicos, de organización y de investigación para buscar entre todos los bienes valiosos susceptibles de conservar. Los posibilidades son diversas y los criterios pueden variar entre comunidades autónomas, por ejemplo no pueden ser el mismo en La Rioja con cientos de yacimientos con icnitas de dinosaurios imposibles de proteger, que otra comunidad que solo tenga un solo yacimiento de estas características, que obviamente debería protegerse.

Cuando se legisla sobre los fósiles no se suele tener en cuenta a un actor fundamental en la paleontología como es el investigador. En el mejor de los casos sufre una carga burocrática generalmente innecesaria, pero en otros la legislación puede llegar a afectar al normal desarrollo de su investigación, bien por la aplicación de las normas de una manera estricta o por malentendidos con las fuerzas de seguridad. El investigador profesional es el que pone en valor a los fósiles, por lo que las leyes y sobre todo su aplicación deberían centrarse en facilitar su trabajo y no entorpecerlo. La mala praxis 
a debate El marco legal para la protección del patrimonio paleontológico. ¿Qué pasa en tu comunidad?

que puede tener algunos "profesionales" no puede ser la excusa para el desarrollo de leyes restrictivas. Además carece de sentido que la burocracia sea la misma para una investigación de una institución pública con una trayectoria contrastada que por ejemplo una actuación de paleontología preventiva de una empresa privada con trabajadores sin experiencia. Una de las maneras de poder reducir la carga burocrática sería por ejemplo el desarrollo planes plurianuales de investigación aprobados por las comunidades autónomas en áreas, yacimientos, tipos de fósiles. Habría otras posibilidades, en definitiva se trataría de desburocratizar la parte de gestión del patrimonio paleontológico aplicable a los profesionales de la investigación. No podemos olvidarnos que profesores de la Universidad e investigadores del CSIC forman parte de la administración como los técnicos de gestión del patrimonio. En este punto vale la pena resaltar que el trabajo conjunto y de colaboración entre los técnicos de la administración y los investigadores es imprescindible para que la información fluya con facilidad.

No quiero acabar estas reflexiones sin apuntar otro aspecto fundamental. Las leyes de patrimonio se han desarrollado para protegerlo, sin embargo la percepción de muchos investigadores es que terminan siendo un instrumento de control de la administración, más que de gestión. Dicho de otra manera, el desarrollo de estas leyes no se han traducido en un aumento de los recursos económicos para la investigación, a pesar de ser paso previo e imprescindible en la valoración del patrimonio paleontológico y su protección. La percepción sería muy diferente si hubiera planes de investigación centrados en líneas o yacimientos significativos, ya que los recursos no son inagotables. Además de, por supuesto, la investigación centrada en catalogación de yacimientos, de fósiles, de conservación en museos, etc., que deberían estar dotados de una manera adecuada.

En resumen, la adecuada gestión patrimonial de los fósiles necesita unos cambios legislativos significativos en las leyes que desarrollen las singularidades del patrimonio fosilífero, en cuanto a su extracción y excavación. Lo importante no es que los fósiles estén gestionados como patrimonio cultural o natural, sino que donde se gestionen se tenga en cuenta sus particularidades. Hay un sentimiento bastante generalizado por parte de los investigadores paleontólogos de que las leyes patrimoniales solo sirven para entorpecer su trabajo, y no hay unas contrapartidas en forma de ayudas a la investigación o de gestión de las colecciones recuperadas. La corrección de dos aspectos son fundamentales para avanzar en una adecuada gestión del patrimonio paleontológico. 